\title{
Correction to: Bone marrow pericyte dysfunction in individuals with type 2 diabetes
}

\section{Giuseppe Mangialardi ${ }^{1}$ - David Ferland-McCollough ${ }^{1} \cdot$ Davide Maselli $^{1,2,3} \cdot$ Marianna Santopaolo $^{1} \cdot$ Andrea Cordaro $^{1}$. Gaia Spinetti $^{2} \cdot$ Maria Sambataro $^{4} \cdot$ Niall Sullivan $^{5} \cdot$ Ashley Blom $^{5} \cdot$ Paolo Madeddu $^{1}$}

Published online: 21 May 2019

(C) Springer-Verlag GmbH Germany, part of Springer Nature 2019

\section{Correction to: Diabetologia}

https://doi.org/10.1007/s00125-019-4865-6

Unfortunately, three errors were made in the conversion of $\mathrm{HbA}_{1 \mathrm{c}}$ to per cent values. The corrections are shown in bold in the text and table below:

\section{Inclusion and exclusion criteria}

Type 2 diabetes was diagnosed according to the American Diabetes Association guidelines and was defined as follows: (1) patient/referring doctor reports a previous diagnosis of diabetes; (2) $\mathrm{HbA}_{1 \mathrm{c}}>48 \mathrm{mmol} / \mathrm{mol}(\mathbf{6 . 5 \%})$ and (3) off insulin for at least 12 months after diagnosis.

Table 1 Characteristics of participants

\begin{tabular}{lll}
\hline Characteristic & Without diabetes & With diabetes \\
\hline Participants, $n$ & 25 & 14 \\
Age, years & $65 \pm 2(39-84)$ & $67 \pm 3(41-79)$ \\
Men/women, $n$ & $11 / 14$ & $7 / 7$ \\
$\mathrm{BMI}_{\mathrm{N}} \mathrm{kg} / \mathrm{m}^{2}$ & $29 \pm 1(21-42)$ & $33 \pm 2(24-44)$ \\
$\mathrm{HbA}_{1 \mathrm{c}}, \mathrm{mmol} / \mathrm{mol}$ & $40 \pm 1$ & $60 \pm 4$ \\
$\mathrm{HbA}_{1 \mathrm{c}}, \%$ & $\mathbf{5 . 8} \pm \mathbf{0 . 1}$ & $\mathbf{7 . 6} \pm \mathbf{0 . 4}$ \\
\hline
\end{tabular}

Data are mean $\pm \mathrm{SD}$ (range) or mean $\pm \mathrm{SD}$, unless stated otherwise

The online version of the original article can be found at https://doi.org/10. 1007/s00125-019-4865-6

Paolo Madeddu

mdprm@bristol.ac.uk

1 Bristol Heart Institute, University of Bristol, Bristol Royal Infirmary, Level 7, Upper Maudlin Street, Bristol BS2 8HW, UK

2 IRCCS Multimedica, Milan, Italy

3 Department of Biochemistry, University of Sassari, Sassari, Italy
Department of Specialized Medicines, Endocrine, Metabolic and Nutrition Diseases Unit, Santa Maria of Ca' Foncello Hospital, Treviso, Italy

5 Muscloskeletal Research Unit, School of Clinical Sciences, University of Bristol, Bristol, UK 